\title{
Using Digital Images to Characterize Canopy Coverage and Light Interception in a Processing Tomato Crop
}

\author{
C. Campillo ${ }^{1}$, M.H. Prieto, C. Daza, M.J. Moñino, and M.I. García \\ Centro de Investigación Finca "La Orden-Valdesequera", Consejería de \\ Infraestructuras y Desarrollo Tecnológico, Junta de Extremadura, 06187 \\ Guadajira (Badajoz), Spain
}

Additional index words. photosynthetically active radiation, low-lying crops, percent of ground cover, crop canopy

\begin{abstract}
Canopy light interception (LI) is a determining factor for crop growth and yield. Crop yield depends on a canopy's capacity to intercept incident solar radiation, which in turn depends on the available leaf area, its structure, and its efficiency in converting the energy captured by the plant into biomass. Digital images offer a series of advantages over other methods of LI estimation, including the possibility to directly process images by computer for which free software is available. The objectives of this work were to develop a simple, economical method for determining LI in low-lying crops such as processing tomato using digital images obtained with a standard, commercial camera and free software and to evaluate the influence of different types of soil coverage (bare soil and plastic mulch) on LI. Photographs of the selected areas were taken using a digital camera at a distance of $160 \mathrm{~cm}$ above the center of each area. The resulting digital images were then analyzed with the free software GIMP 2.2 and IMAGE J. Three methods [area (SA), contour (SC). and reclassification (SR)] were used to quantify the percentage of groundcover (PGC). They were applied to the same images and compared with $L I$ as measured with a line quantum sensor at solar noon. There was a close relationship between LI and estimated PGC with all three methods and for different soil cover regimes. In all cases, there was a linear adjustment with a significant correlation coefficient $(P<0.01)$ and an $r^{2}$ of greater than 0.88 . The adjustment with RI was narrowest when the SR method was used to estimate PGC $\left(r^{2}=0.93\right)$ followed by SC $\left(r^{2}=\right.$ $0.92)$ and SA $\left(r^{2}=0.88\right)$. Measurements of LI based on digital images offered practical advantages with respect to the use of photosynthetically active radiation bars because the latter must be used at solar noon. In contrast, measurements obtained with a digital camera can be taken at any time of day and bright sunshine is not necessary. Different correlations were obtained for bare soil and plastic mulch conditions, so it was necessary to use a different equation to estimate LI under each condition.
\end{abstract}

The interception of light by a canopy is a determining factor in crop development and provides the energy needed for fundamental physiological processes such as photosynthesis and transpiration. Crop yield depends on a canopy's capacity to intercept incident solar radiation, which in turn depends on the available leaf area, its structure, and its efficiency in converting the energy captured by the plant into biomass (Gifford et al., 1984). Most production strategies are directed toward maximizing the interception of solar radiation. In the case of crops, this implies adapting agricultural practices in such a way as to obtain complete canopy cover as soon as

Received for publication 25 Feb. 2008. Accepted for publication 18 June 2008

This work was carried out as part of the INIA project RTA04-060-C6-03 and was cofinanced by FEDER funds.

${ }^{1}$ To whom reprint requests should be addressed; e-mail carlos.campillo@juntaextremadura.net. possible (Gardner et al., 1985). Deficiencies in water and nutrient inputs may reduce the rate of leaf growth, reducing yield below optimum levels as a result of insufficient energy capture (Loomis and Connor, 2002). Quantifying the intercepted radiation is therefore an important consideration when studying the incidence of different agricultural or environmental factors on yield, and it is the main source of data in the most widely used methods for estimating crop water needs (Allen et al., 1998).

From a practical point of view, the solar radiation spectrum is divided into regions, each with its own characteristic properties. Appropriate procedures and sensors must be chosen according to the specific objectives of the radiation measurements (Jones et al., 2003). Visible radiation, between the wavelengths of 400 and $700 \mathrm{~nm}$, is the most important type from an ecophysiological viewpoint because it relates to photosynthetically active radiation $(P A R)$. A direct method for determining the percentage of intercepted radiation
(LI) is to measure PAR both above and below the canopy at noon on completely cloudless days (Board et al., 1992; Purcell, 2000; RetaSánchez and Fowler, 2002) and then apply the following Eq. [1]:

$$
\mathrm{LI}=\left|1-\left(\frac{\text { Par below canopy }}{\text { Par above canopy }}\right)\right|
$$

Commercially available lineal PAR sensors are used to take these measurements, which are based on $P A R$ values registered by the sensor. These measurements can be taken either by locating sensors perpendicular to the crop rows (Egli, 1994) or by taking multiple measurements parallel to them (Board et al., 1992). The latter method can be costly according to the number of measurements needed to characterize the study area, especially in the case of low-lying crops, in which it may be necessary to remove vegetation to place sensors under it, which also has the drawback of introducing alterations during data collection. We therefore decided to use the percentage of shaded soil at solar noon or the percentage of groundcover (PGC) to estimate LI; this is an easier and more economical way to obtain the required data (Fakorede and Mock, 1977; Morgan and Brown, 1983; Williams et al., 1965). It is generally assumed that the shaded area at soil level corresponds to the fraction of incident radiation that has been intercepted by the crop. This is an approximation that is valid as long as the percentage of light transmission through the leaves is small in comparison with its absorption. The precision with which PGC estimates LI will therefore depend on how well the shaded area is defined and on the capacity of the canopy to capture all of the radiation within the shaded area. In this second case, estimates could be improved by taking complementary measurements of radiation at a sufficient number of points within the shaded area to characterize the radiation traversing the canopy (Lang et al., 1985).

Some of the methods used to determine PGC involve visual estimates (Olmstead et al., 2004; Ortega-Farías et al., 2004). Methods such as the "interception line" (Gallo and Daughtry, 1986; Molloy and Moran, 1991), the analysis of the intersection of shadows on metric strips, and paper drawings of the sampling areas (Adams and Arkin, 1977; Bolstad and Grower, 1990; Smith et al., 1999) were used to determine PGC in a nondestructive way. However, to apply these last three methods, cloudless days are needed as are a sufficient number of measurements at different orientations to allow a reliable characterization of the area (Ewing and Horton, 1999). The precision of the visual estimation method varies, because it depends on the skill of the operator; results will not be comparable when several people are involved (Olmstead et al., 2004). Furthermore, it has been shown that coverage values tend to be overestimated (Olmstead et al., 2004). In the cases of the interception line and metric strip methods, similar problems are 
encountered as those associated with the use of PAR bars in the case of low-lying crops and it is difficult to take measurements below the canopy. Finally, making paper drawings is very costly when working under field conditions and when a relatively large area must be characterized.

The inherent difficulties in measuring $P A R$ throughout a canopy and advances in radiometric techniques have led to the development of methods for remotely sensing radiation capture. Radiometric methods rely on differences in the spectral reflectance of vegetation and soil. Vegetative indices based on reflectance in broad wavebands have provided good estimates of radiation capture and yield in crop plants (Gallo et al., 1985; Hatfield et al., 1984). Vegetation indices have also provided good estimates of fractional groundcover (Boissard et al., 1992; White et al., 2000). More recently, spectroradiometers capable of measuring narrow band radiation have been used to monitor plant stress (Elvidge and Chen, 1995). Radiometric satellite data are now available for the evaluation of large areas, and small portable radiometers are becoming less expensive as the technology progresses. In this respect, good results have been obtained with measurements using digital photographic images to determine crop cover and radiation interception in soybean (Purcell, 2000) and lettuce (Klassen et al., 2003), crop cover in turfgrass (Richardson et al., 2001), and canopy and soil cover with straw mulch (Bennet et al., 2000; Beverly, 1996; Olmstead et al., 2004). It is possible to assimilate into the LI formula [Eq. 1] the fraction of the area occupied by the crop canopy when the sun is at its highest point (Purcell, 2000). Other important points are that the area of soil exposed to the sun can be differentiated from that covered by leaves while the angle of the camera is close to that of the sun (Purcell, 2000). With regard to differentiating between the green parts of the crop and the soil surface, results could vary in the case of soils of different colors as a result of their different behavior with respect to the reflection and absorption of radiation; this is particularly the case for different kinds of mulches. In this case, the validity of the method will largely depend on the capacity of the software to discriminate between parts of the crop's green canopy. In the presence of weeds or green cover, it may be necessary to prescreen images.

Digital images offer a series of additional advantages over other methods for estimating LI assuming that the soil background can be distinguished from leaves, light transmission of leaves is small relative to light absorption, and that the angle of the camera to the horizon approximates the solar angle (Purcell, 2000) such as the direct treatment of images by computers. Moreover, a graphic record of the crop is generated in the case of studies of canopy evolution. This can be used for phenological monitoring (Shelton et al., 1988) to determine differences in color and fertility in maize (Ewing and Horton, 1999) and to study the incidence of pests and diseases.

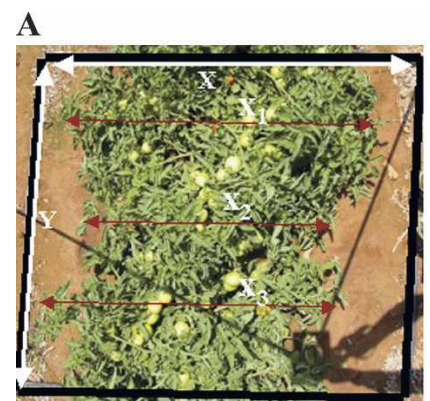

B

C
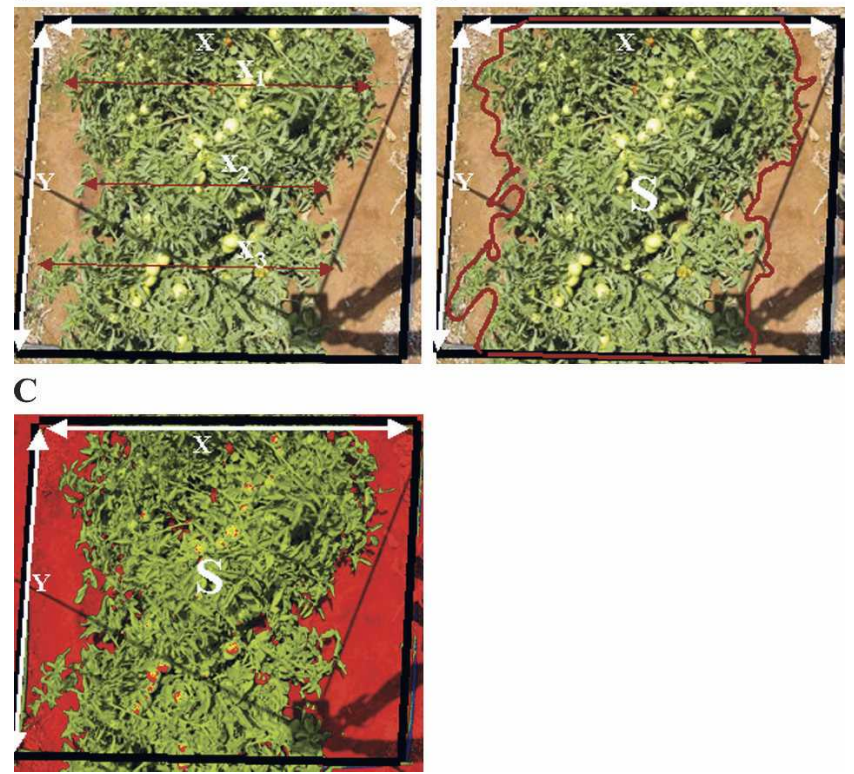

Fig. 1. Digital images of processing tomato to which the three methodologies for estimation percentage of groundcover were applied. In the three images, $\mathrm{X}$ and $\mathrm{Y}$ mark the dimensions of the reference rectangle: (A) area method. $\mathrm{x}_{1}, \mathrm{x}_{2}, \mathrm{x}_{3}$ are crop row widths at three points chosen at random within the reference rectangle; (B) contour method. $\mathrm{S}$ is the crop area within the reference rectangle; (C) reclassification method. $\mathrm{S}$ is the crop area within the reference rectangle.
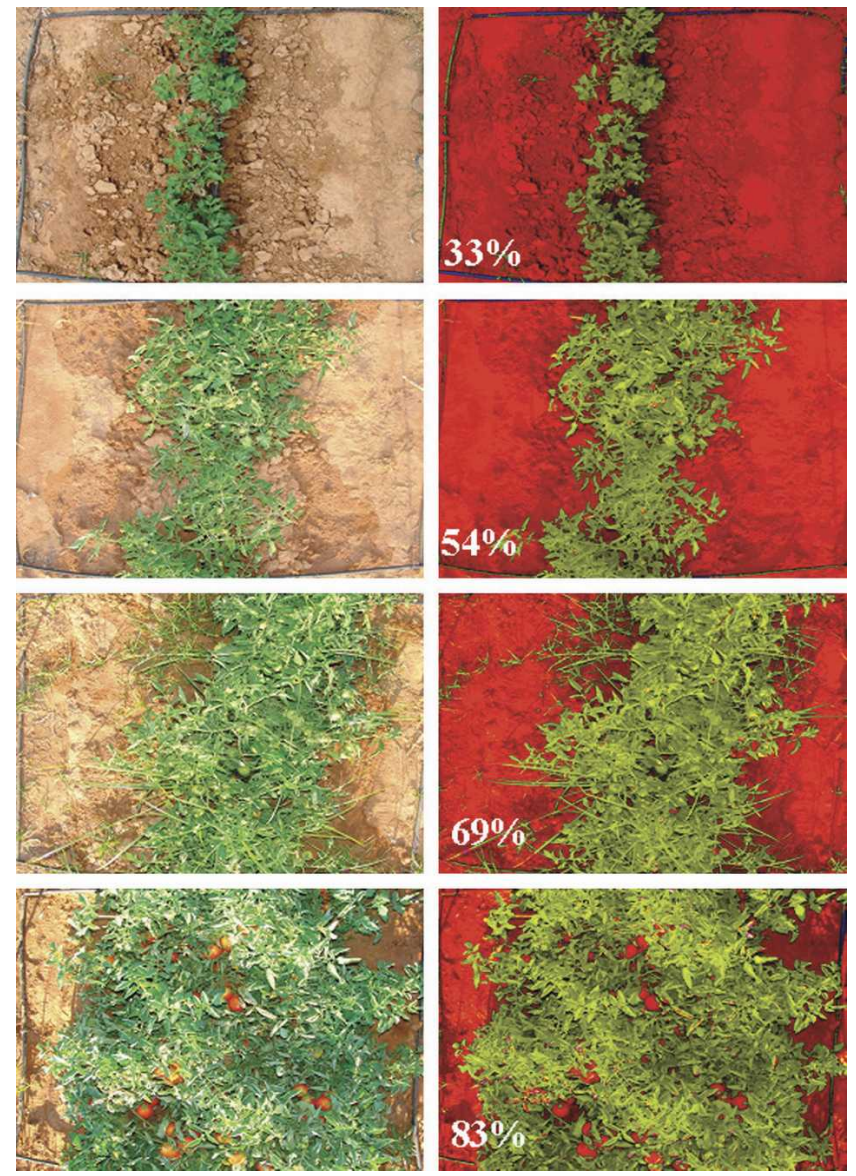

Fig. 2. Evolution of the percentage of ground cover throughout the crop cycle, calculated using the reclassification method (SR) for the same trial plot with bare soil. The numbers in the left bottom part of each figure correspond to percentage of groundcover. 
The objective of this work was to develop a simple, economical method for determining LI in low-lying crops such as processing tomato using digital images obtained with a commercial camera and freely available software and to evaluate the influence of different degrees of soil coverage.

\section{Materials and Methods}

\section{Location and cropping details}

The experiment was conducted during two consecutive summers (2005 to 2006) at an experimental station (Junta de Extremadura) in Guadajira, Spain (38 53' N and $6^{\circ} 50^{\prime} \mathrm{W}$ ) on a slightly acid, sandy loam soil. The soil was shaped in 1.5 -m-wide beds. A processing tomato crop (var. Odin) was transplanted in single rows with a distance between plants of $20 \mathrm{~cm}(33,333$ plants/ha). The field was drip-irrigated from transplant to harvest with a single irrigation line per row.

The experimental design was a split plot with three complete blocks. Two soil management regimes were used in the main plot: bare soil (T) and plastic-cover mulch (P) covered with 120 -cm-wide, 25 - $\mu \mathrm{m}$-thick, black, plastic biodegradable matter (Mater-Bi ${ }^{\circledR}$, Novament, Italy). In the subplot, three irrigation regimes were established to measure the crop evapotranspiration (ETc): $\mathrm{T} 125$ and $\mathrm{P} 125=$ $1.25 \mathrm{ETc}, \mathrm{T} 100$ and $\mathrm{P} 100=\mathrm{ETc}$, and $\mathrm{T} 75$ and $\mathrm{P} 75=0.75$ ETc. The different treatments allowed different degrees of plant soil coverage at different points in the crop cycle.

\section{Measurements}

Percent of ground cover. A $120 \times 150-\mathrm{cm}$, rectangular, polyethylene tubing frame was set up in one crop row in each elementary plot identifying a representative area containing six plants. Photographs of the selected areas were taken using a commercial camera (Sony Digital Still Camera DSC828 with a resolution of eight megapixels) (Sony, Tokyo) from a distance of $160 \mathrm{~cm}$ above the center of each group of plants. The data were collected at solar noon coinciding with the taking of lineal $P A R$ sensor measurements. Photographs were taken at 10 -d intervals with a total of 12 measurements for each crop cycle. This began $2 \mathrm{~d}$ after transplantation and ended at harvest.

GIMP 2.2 free software (www.gimp.org/ downloads) was used to analyze the digital images and differentiate between vegetation and soil or plastic by means of a color reclassification process. As mentioned subsequently, IMAGE J 1.33 free software (rsb.info.nih.gov/ij/) was used to delimit the areas shown in the images and to measure lengths and areas within them.

Three methods of analysis were used to quantify the PGC and they were all applied to the same image. With each of these methods, we obtained an estimate of the percentage of shaded soil in each digital image. The shade created by the tripod was easily discriminated in the photographic analysis.

Area method (SA). In this method, crop row width was estimated by simulation based on measurements taken at three points within the marked area using a metric strip. These data were then used to estimate average row width and the PGC (Adams and Arkin, 1977; Giménez, 1985). Both row and frame width were determined in pixels using the measuring tool (IMAGE J 1.33). The sampling area was delimited by the width $(X)$ and length $(Y)$ of the reference frame (Fig. 1A) and the three measurements of row width were: $x_{1}$, $x_{2}, x_{3}$. PGC was calculated through the expression:

$$
\mathrm{PGC}=\left(\frac{\left(\frac{x_{1}+x_{2}+x_{3}}{3}\right) \times Y}{(X \times Y)}\right) \times 100
$$

Contour method (SC). In this method, the technique of drawing the crop's shade contour on paper and the subsequent measurement of the area in question is simulated (Kvet and Marshall, 1971). Figure 1B shows the processing of the digital image. To measure the area, the crop's contour was previously delimited using the IMAGE J 1.33 program. Areas with no vegetation cover that were within the canopy were measured and omitted from the surface area count. The crop surface area $(\mathrm{S})$ was measured in pixels using the same program. This area was then related to the sampling area to estimate the PGC according to the following expression:

$$
\mathrm{PGC}=\left(\frac{S}{X \times Y}\right) \times 100
$$

Reclassification method (SR). With this method (Fig. 1C), the crop area (S) is determined by classifying the image according to the range of radiation levels shown on an RGB image of the crop ( 0 to 255 colors); this was done using a RGB max reclassification tool (GIMP 2.2). Figure 2 shows the evolution of the crop, using digital imagery, both before and after applying color reclassification. After the classification process, it is possible to measure the surface area occupied by green parts (crop) and to differentiate them from the soil or plastic. In contrast to the other two methods, here the crop must be subject to

$$
\mathrm{PGC}=\left(\frac{S}{X \times Y}\right) \times 100
$$

Intercepted radiation. LI measurements were made using a $100-\mathrm{cm}$ linear $P A R$ sensor (LICOR Li-190; LI-COR, Lincoln, NE). They were made at solar noon, perpendicular to the crop row, in the same area in which the photographs had been taken. Samples taken from below the crop were compared with reference measurements taken above the crop row (ref). Percentages of LI were calculated by applying Eq. [5], in which it was necessary to know the percentage of radiation that was not intercepted by the crop (RP) as a quotient of the PAR measurements taken both above and below the canopy. According to the degree of plant development two situations for measurement of RP were proposed:

1. When the crop row width was less than $100 \mathrm{~cm}$ (Fig. 3A), RP was calculated by applying Eq. [6] as the average of five measurements taken under the crop $\left(r_{1}\right.$, $\left.r_{2}, r_{3}, r_{4}, r_{5}\right)$. Measurements were taken every $20 \mathrm{~cm}$ using the total length of the $P A R$ bar $(100 \mathrm{~cm})$ and adding $50 \mathrm{~cm}$ to the reference measurement to include the total width of crop (150 $\mathrm{cm})$. In this situation, ref was measured using the total length of the $P A R$ bar.

2. When the crop row width was greater than $100 \mathrm{~cm}$ the maximum length of the $P A R$ sensor (Fig. 3B), RP was calculated applying Eq. [7] as the average of three measurements taken beneath the crop on each side of the crop row $\left(r_{1}, r_{2}, r_{3}\right.$ left side and $r_{4}, r_{5}, r_{6}$ right side). Measurements were taken at $20-\mathrm{cm}$ intervals using a half-length $P A R$ bar $(50 \mathrm{~cm})$. The sensor was covered with a material that blocks light and average measurements were taken in the center of the row $\left(r_{7}, r_{8}\right)$, also using a half-length $P A R$ bar $(50 \mathrm{~cm})$. This was done in a way that included the total width of culture (150 $\mathrm{cm})$. In this situation, ref was measured using a half-length $P A R$ bar $(50 \mathrm{~cm})$.

$$
\mathrm{LI}=(1-\mathrm{RP}) \times 100
$$

$$
\begin{gathered}
\mathrm{RP}=\left(\frac{\left[\operatorname{mean}\left(r_{1} ; r_{2} ; r_{3} ; r_{4} ; r_{5}\right)+0.5 \times \operatorname{mean}\left(r_{c f}\right)\right]}{[\operatorname{mean}(r c f) \times 3]}\right) \\
\mathrm{RP}=\left(\frac{\left\{\operatorname{mean}\left(r_{1} ; r_{2} ; r_{3}\right)+\left[\operatorname{mean}\left(r_{4} ; r_{5} ; r_{6}\right)+\operatorname{mean}\left(r_{7} ; r_{8}\right)\right]\right\}}{\left[\operatorname{mean}\left(r_{c f}\right) \times 3\right]}\right)
\end{gathered}
$$

homogeneous lighting conditions, because the presence of shadows may reduce a crop's color and impede subsequent color reclassification. PGC was calculated according to the formula:
This procedure was carried out in the same area in which the photographs had been taken and with the same frequency.

Data analysis involved an analysis of covariance between regressions (Peña, 
A
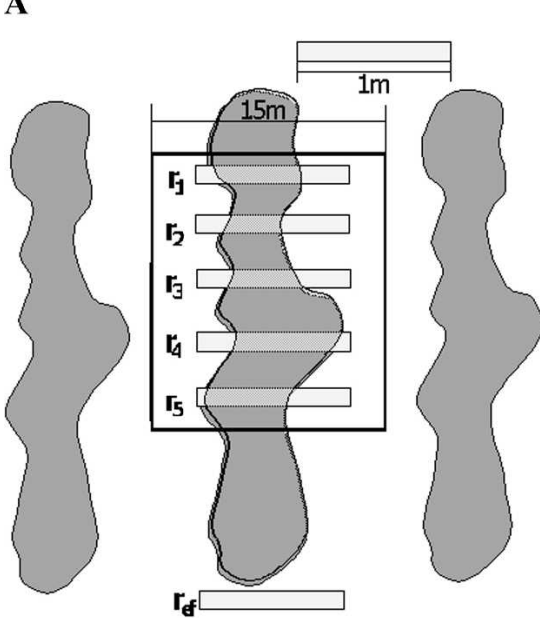

B

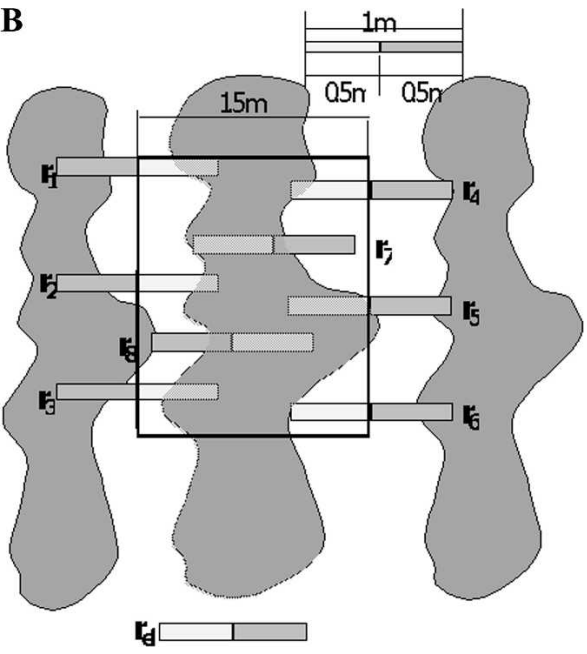

Fig. 3. Measuring procedure used to determine the value of intercepted radiation in a tomato crop using photosynthetically active radiation measuring bars (A) for measurements with low crop development ( $>1 \mathrm{~m}$ wide) and (B) measurements with high crop development $(<1 \mathrm{~m}$ wide). The measuring zone of the bar is indicated in yellow.

1987) with the statistical package SPSS version 13 for Windows (SPSS, Chicago, IL).

\section{Results and Discussion}

Estimating light interception from digital images. Figure 4 shows that there was a close relationship between the fraction of light intercepted by the canopy at solar noon and estimated PGC for all three methodologies in both years and under all irrigation regimes with both bare soil and plastic mulch. In all cases, there was a linear adjustment with a significant correlation coefficient $(P<0.01)$ and an $r^{2}$ greater than 0.87 . This indicates that any of the described methods would have been valid for estimating the amount of radiation intercepted by the crop.

However, the adjustment was different according to the method used. The adjustment with LI was narrower when using the SR method to estimate PGC $\left(r^{2}=0.92\right.$ and $0.96)$ followed by SC ( $r^{2}=0.91$ and 0.95$)$ and SA $\left(r^{2}=0.87\right.$ and 0.94$)$ for 2005 and 2006, respectively. The relationship between LI and PGC was somewhat stronger when the SR and SC methods were used, whereas the SA method produced greater errors in estimation. Because the measurement of crop row width was simulated in SA, a considerable area of bare soil was counted as vegetation (Fig. 1A); this explains the slightly higher values for PGC than with the other methods. In the case of SC, an attempt was made to produce a method for drawing the shaded area of the crop to estimate the PGC; quite good results were obtained. With this second method, a greater proportion of bare soil was excluded than with SA (Fig. 1B). Finally, the most accurate estimate of PGC for both crops was obtained with SR, because color discrimination made it easier to differentiate between vegetation and soil (Fig. 1C). Although the results obtained with SR and $\mathrm{SC}$ were similar, it should be borne in mind that the SR method was cheaper to apply because all image processing was performed by software without the need for human definition of the area to be measured. The use of processed digital images with the SR method supposed a considerable improvement with respect to the other two methods and also in the gathering of data directly from the crop. This method was economical and easy to apply. It also eliminated the subjectivity associated with operators having to define areas or points of measurement. Slight but significant differences were found between years applying the same methodology with the adjustment being better in 2006 . This was probably because a wider range of data was considered for that year (from transplant to harvest). The correlations were highly significant, even for water stress treatments (75\% ETc) and taking into account that in tomato plants, water stress promotes changes in PGC and leaf angle.

Comparing the linear regression obtained between LI and PGC for the same crop but with different soil covers (bare soil and plastic mulch) (Table 1), the same gradients were obtained with the SA and SC methods regardless of the cover regime. In these cases, discrimination between the soil and crop was performed manually by an operator who applied similar criteria in both cases. There were, however, differences when applying the SR method; the computer software encountered greater difficulty discriminating between plastic and vegetative cover. This meant that the fitting of the linear regression was not as $\operatorname{good}\left(r^{2}=0.95\right.$ for soil and 0.92 for plastic), although it still remained high and significant. Linear regressions obtained for the same crop but with different soil covers were significantly different. This implied that it would be necessary to use a different relationship according to the particular soil management regime applied (Table 1).

The correlation line between LI and PGC did not pass through the 1:1 line in any of the methods used (Fig. 4). In the case of crops such as processing tomato, whose leaves were at various levels and/or of irregular shapes and sizes, moreover, the area defined as shade was not opaque to the passage of radiation. As a result, the proportion of radiation intercepted was lower than for the shaded soil, even when we applied the SR method, which eliminated the spaces without vegetation inside the canopy. However, when applications of the same methodologies were compared for another horticultural crop with a different kind of leaf such as cauliflower (data not provided), the fitting relationship approached 1:1 with both the SR and SC methods. The cauliflower has regularly shaped, large leaves that are thick enough to absorb most of the incident radiation and defining the canopy based on digital images therefore provides estimated values that are more closely adjusted to the amount of radiation intercepted. For lettuce and beet, Tei et al. (1996) also obtained data with a gradient of close to the 1:1 line, which resembled the behavior of cauliflower with regard to LI. On the other hand, Richardson et al. (2001), studying grass, and Wilhelm et al. (2000), working with maize, obtained regressions that deviated from the 1:1 line and were similar to that obtained for tomato. Working with soybean, Purcell (2000) also obtained a regression gradient that coincided with the 1:1 line. Factors such as the influence of diffuse radiation and radiation reflection from soil to crop canopy, crop height, and leaf angle affect groundcover and radiation interception in different ways and can therefore influence the relationship between PGC and LI, even for the same crop under different situations. Leaf angle can cause digital imaging to underestimate $P A R$ absorption. This is most evident with vertical leaves that will appear to have virtually $0 \%$ groundcover but still absorb radiation (Klassen et al., 2003). Another reason for the observed divergence between LI and PGC could be differences between the angle of the sun and the position of the camera (perpendicular to the soil) with regard to the soil surface when taking photographs. According to Purcell (2000), for crops with a leaf area index (LAI) greater than 1 , the error in the prediction of LI based on measurements of soil cover is generally small: less than 0.08 $\mathrm{cm}^{-2} \cdot \mathrm{cm}^{-2}$, provided that the difference between the maximum height of the sun and the angle of the camera is less than $25^{\circ}$. In our case, the difference was $40^{\circ}$ at the start of the crop cycle and $15^{\circ}$ in the middle of the cycle. Although the angle was sometimes greater than the maximum value indicated by Purcell (2000), there were no important differences with regard to LI measurement, so this aspect does not seem to be very important for this kind of low-lying crop.

Nevertheless, the three proposed methods enable a good estimation of LI applying traditional methods such as the line quantum sensor. We therefore have a valid tool that can be used to rapidly characterize plant canopies and easily study the incidence of 

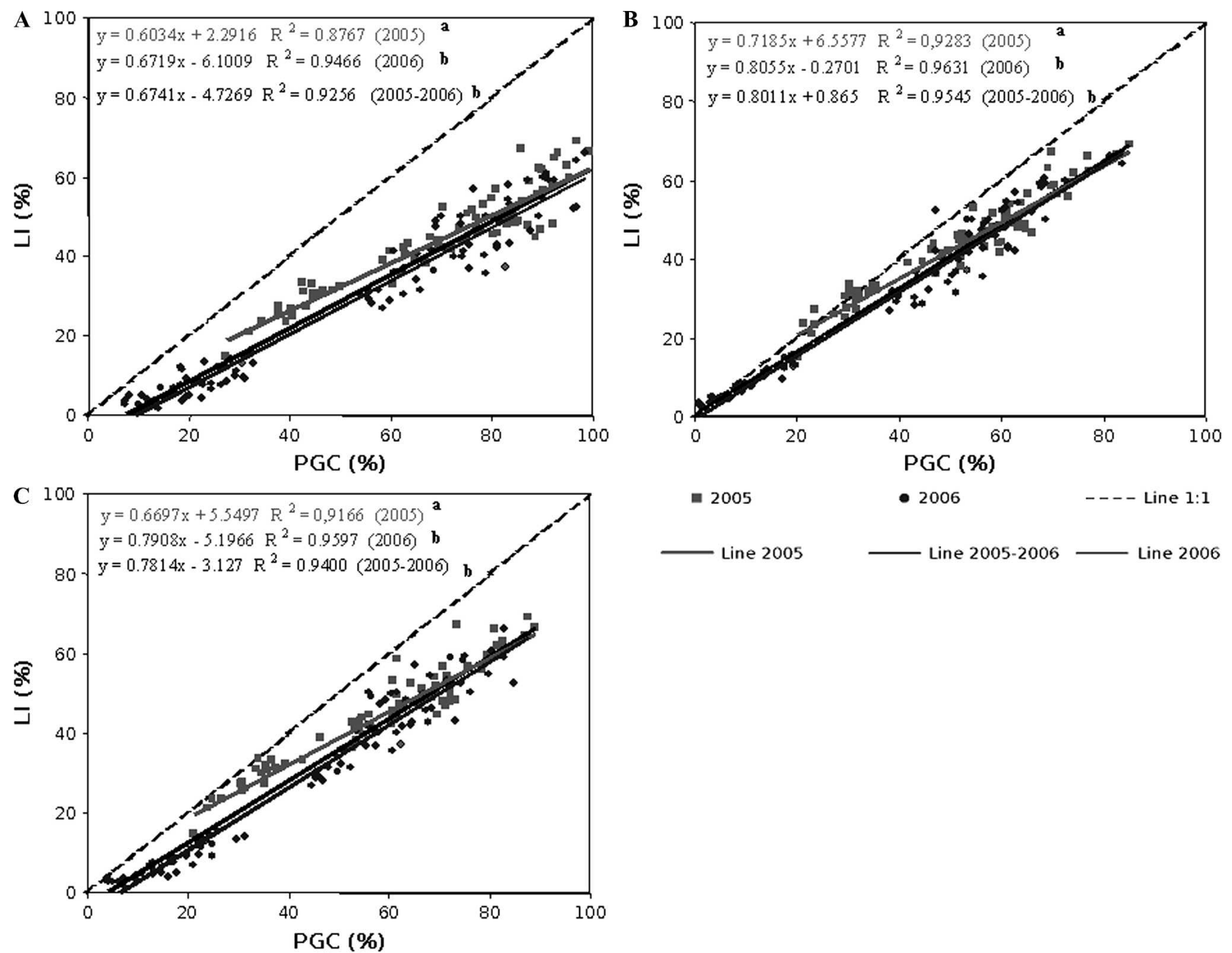

Fig. 4. Relationship between canopy percent light interception (LI) and percentage of groundcover (PGC) determined by the different methods of analysis: area (A), contour (B), and reclassification $(\mathbf{C})$ for the tomato crop in 2005 and 2006. Values with different letters differ $(P<0.05)$ between years.

Table 1. Values of the parameters of the interception point (a), gradient (b), and determination coefficient $\left(r^{2}\right)$ of each regression line $(\mathrm{y}=\mathrm{a}+$ bx) between the percentage of groundcover (PGC) estimated using the area (SA), contour (SC), and reclassification (SR) and canopy light interception (LI) methods with bare soil (soil) and plastic covering (plastic) and considering both years on the same line.

\begin{tabular}{|c|c|c|c|}
\hline Methods & $r^{2}$ & $\mathrm{a}$ & $\mathrm{b}$ \\
\hline \multicolumn{4}{|l|}{ Method SA } \\
\hline Soil & 0.950 & -4.510 & 0.669 \\
\hline Plastic & 0.889 & -5.124 & 0.610 \\
\hline Soil and plastic & 0.926 & -4.727 & 0.674 \\
\hline Significant difference & & NS & NS \\
\hline \multicolumn{4}{|l|}{ Method SC } \\
\hline Soil & 0.955 & -2.809 & 0.771 \\
\hline Plastic & 0.919 & -3.739 & 0.797 \\
\hline Soil and plastic & 0.940 & -3.127 & 0.781 \\
\hline Significant difference & & NS & NS \\
\hline \multicolumn{4}{|l|}{ Method SR } \\
\hline Soil & 0.969 & 1.815 & 0.802 \\
\hline Plastic & 0.941 & -0.701 & 0.813 \\
\hline Soil and plastic & 0.955 & 0.865 & 0.801 \\
\hline Significant difference & & * & NS \\
\hline
\end{tabular}

important factors such as water needs, yield, and so on, on canopy development.

Seasonal evolution of soil cover. Figure 5 shows the seasonal evolution of PGC in 2005 for the $100 \%$ ETc soil treatment. This shows that there were clear differences between the values obtained according to the methodology used, assuming for the lineal $P A R$ sensor that LI $=$ PGC. The SA method provided the highest values, whereas there were marked differences between the results obtained with the other two methods and PAR measurements. These could be scaled in the following order: $\mathrm{SA}>\mathrm{SC}>\mathrm{SR}>P A R$. Although the reclassification method most closely approximated real intercepted radiation values, it still considerably overestimated them because individual leaves and plants never absorb $100 \%$ of the incident light. This is especially evident at canopy closure $(100 \%$ groundcover) when canopy $P A R$ absorption remains below $100 \%$. Canopies will have a higher PAR absorption per unit groundcover as leaf angle, LAI, chlorophyll content, increase and thus have a groundcover to $P A R$ absorption ratio closer to $1: 1$. Of these factors, only increased leaf angle can cause digital imaging to underestimate $P A R$ absorption. This is most evident with a vertical leaf that will appear to have virtually $0 \%$ groundcover but still absorbs radiation. It would therefore be necessary to use the linear relationship presented in the previous section if the objective was to estimate LI based on digital images (Klassen et al., 2003). The increase in PGC $211 \mathrm{~d}$ after transplanting (Fig. 5) was the result of the ripeness of a large percentage of the fruits. It is normal for new shoots to emerge when the climatic conditions are favorable (low temperatures and available water).

All three methods proposed offer the advantage that no contact with the canopy is required. For tomato crops, after the first red fruits have formed, measurement with a $P A R$ bar is practically impossible. This has led many authors (Daughtry and Hollinger, 1984; García et al., 2001; Kvet and Marshall, 1971; Ross et al., 2000) to use more rapid methods such as the measurement of crop 


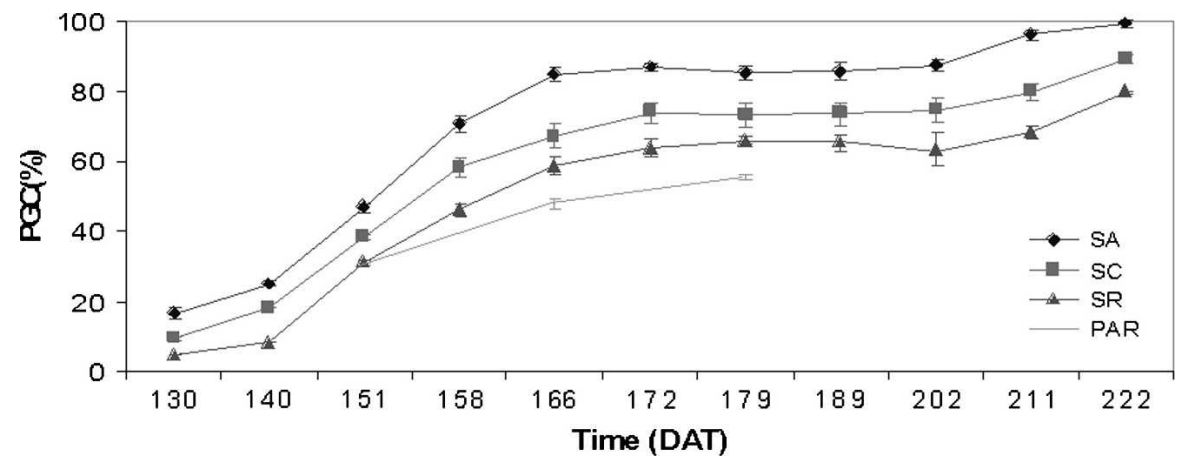

Fig. 5. Time course of the percentage of shaded soil throughout the tomato crop cycle considering the days after transplanting (DAT) for the different measurement methods: area (SA), contour (SC), reclassification (SR), and linear sensor (photosynthetically active radiation), for the bare soil treatment with $100 \%$ and so on. Each point is the average of three plots. The bars represent SE of the mean.

widths with tape measures and volumetric methods (Patón et al., 1998). These are compatible with the area method and produce results that are less reliable than those produced by the reclassification method.

Measurement of soil cover using photographic methods for low-lying plants such as processing tomato makes it possible to study canopy evolution, which can be monitored without the need to alter their spatial layout. Although intercepted radiation is normally overestimated, with the degree of error depending on the method used, the crop groundcover measurement allows comparing plots subjected to different treatments.

\section{Conclusions}

The three methods used for analyzing the digital images were all shown to be useful for estimating RI for low-lying horticultural crops such as the processing tomato.

Traditional methods used for measuring the shaded soil area such as crop width and drawings of projected shade can be simulated through a process of image analysis, although they tend to overestimate the shaded soil area with respect to values obtained applying the reclassification and contour methods.

The reclassification method produces the values that most closely resemble those of intercepted radiation measured with a $P A R$ bar with a correlation $\approx 95 \%$.

Measurements taken from digital images exhibit practical advantages with respect to the $P A R$ bar, which must be used at solar noon. In contrast, measurements obtained with a digital camera can be taken at any time of the day and full sunshine is not necessary.

The kind of soil cover influenced the correlation between LI and PGC for the reclassification method. It influenced the capacity to discriminate between parts of the plant and the cover. A different regression is therefore needed for each soil coverage system.

\section{Literature Cited}

Adams, J.E. and G.F. Arkin. 1977. A light interception method for measuring row crop ground cover. Soil Sci. Soc. Amer. J. 41:789-792.
Allen, R.G., L.S. Pereira, D. Raes, and M. Smith. 1998. Crop evapotranspiration-Guidelines for computing crop water requirements. FAO Irrigation and Drainage Paper 56.

Bennet, L.T., T.S. Judd, and M.A. Adams. 2000. Close-range vertical photography for measuring cover changes in perennial grasslands. J. Range Manage. 53:634-641.

Beverly, R.B 1996. Video image analysis as nondestructive measure of plant vigor for precision 27:607-614

Board, J.E., M. Karmal, and B.G. Harville. 1992. Temporal importance of greater light interception to increased yield in narrow-row soybean. Agron. J. 84:575-579.

Boissard, P., J.G. Pointel, and J. Tranchefort. 1992. Estimation of the ground cover ratio of a wheat canopy using radiometry. Int. J. Remote Sens. 13:1681-1692. leaf area index in fourteen southern Wisconsin forest stands using a portable radiometer. Tree Physiol. 7:115-124.

Daughtry, C.S.T. and S.E. Hollinger. 1984. Costs of measuring leaf area index of corn. Agron. J. 76:836-841

Egli, D.B. 1994. Mechanisms responsible for soybean yield response to equidistant planting patterns. Agron. J. 86:1046-1049.

Elvidge, D.E. and Z. Chen. 1995. Comparison of broad-band and narrow-band red and nearinfrared vegetation indices. Remote Sensing Environmental. 54:38-48.

Ewing, R.P. and R. Horton. 1999. Quantitative color image analysis of agronomic images. Agron. J. 91:148-153.

Fakorede, M.A.B. and J.J. Mock. 1977. Leaf orientation and efficient utilization of solar energy by maize (Zea mays L.), p. 207-230. In: Agrometeorology of the maize (corn) crop. Proc. Symp. Agrometeorol. Maize (corn) Crop. World Meteorology Organization. Iowa State University, Ames, IA.

Gallo, K.P. and C.S.T. Daughtry. 1986. Techniques for measuring intercepted and absorbed photosynthetically active radiation in corn canopies. Agron. J. 78:752-756.

Gallo, K.P., C.S.T. Daughtry, and M.E. Bauer. 1985. Spectral estimation of absorbed photosynthetically active radiation in corn canopies. Remote Sensing Environmental. 17:221232.

García, M.I., M.H. Prieto, M. Lavado, and M.J. Moñino. 2001. Influencia de dos estrategias de cultivo diferentes sobre el desarrollo, la productividad y la calidad del cultivo de tomate de agriculture. Soil Science and Plant Analysis

Bolstad, P.V. and S.T. Grower. 1990. Estimation of industria. horticultura Ad. Cáceres: IV Congreso Ibérico de Ciencias Horticolas. p. 203-211.

Gardner, F.P., R. Pearce, and R.L. Mitchel. 1985. Carbon fixation by crop canopies, p. 31-57. In: Physiology of Crop Plants. The Iowa State Univ. Press, Iowa.

Gifford, R.M., J.H. Thorne, W.D. Witz, and R.T. Giaquinta. 1984. Crop productivity and photoassimilate partitioning. Science 225:801-808.

Giménez, C. 1985. Resistencia a sequía de cultivares de girasol bajo condiciones de campo. Tesis Escuela Superior De Ingenieros Agrónomos. Universidad de Cordoba.

Hatfield, J.L., G. Asrar, and E.T. Kanemasu. 1984 Intercepted photosynthetically active radiation estimated by spectral reflectance. Remote Sensing Environmental. 14:65-75.

Jones, H.G., N. Archer, E. Rotenberg, and R. Casa. 2003. Radiation measurement for plant ecophysiology. J. Expt. Bot. 54:879-889.

Klassen, S.P., G. Ritchie, J.M. Frantz, D. Pinnock, and B. Bugbee. 2003. Real-time imaging of ground cover: Relationships with radiation capture, canopy photosynthesis, and daily growth rate. Crop Science Society of America Special Publication on Digital Technologies. p. 19.

Kvet, J. and J.K. Marshall. 1971. Assessments of leaf area and other assimilating plant surfaces. Z.sesták jc, and p.g. jarvis, The Hague, The Netherlands. p. 517-574.

Lang, A.R.G., X. Yuequin, and J.M. Norman 1985. Crop structure and the penetration of direct sunlight. Agr. For. Meteorol. 35:83-101.

Loomis, R.S. and D.J. Connor. 2002. Crop ecology: Productivity and management in agricultural system. Cambridge University Press, Cambridge, UK.

Molloy, J.M. and C.J. Moran. 1991. Compiling a field manual from overhead photographs for estimating crop residue cover. Soil Use and Management. 7:177-182.

Morgan, J.A. and R.H. Brown. 1983. Photosynthesis and growth of bermudagrass swards. I. Carbon dioxide exchange characteristics of swards mowed at weekly and monthly intervals. Crop Sci. 23:347-352.

Olmstead, M.A., R. Wample, S. Greene, and J. Tarara. 2004. Nondestructive measurement of vegetative cover using digital image analysis. HortScience 39:55-59.

Ortega-arías, S., Calderón, R., Martelli, N., and Antonioletti, R. 2004. Evaluación de un modelo para estimar la radiación neta sobre un cultivo de tomate industrial. Agricultura técnica $64: 1-11$

Patón, D., P. Azocar, and J. Tovar. 1998. Growth and productivity in forage biomass in relation to the age assessed by dendrochronology in the evergreen shrub Cistus ladanifer (L.) using different regression models. J. Arid Environ. 38:221-235.

Peña, D. 1987. Estadistica. Modelos y métodos 2. Modelos lineales y series temporales. Universidad A, Madrid, Spain.

Purcell, L.C. 2000. Soybean canopy coverage and light interception measurements using digital imagery. Crop Sci. 40:834-837.

Reta-Sánchez, D.G. and J.L. Fowler. 2002. Canopy light environment and yield of narrow-row cotton as affected by canopy architecture. Agron. J. 94:1317-1323.

Richardson, M.D., D.E. Karcher, and L.C. Purcell. 2001. Quantifying turfgrass cover using digital image analysis. Crop Sci. 41:1884-1888.

Ross, V., J. Ross, and A. Koppel. 2000. Estimation of leaf area and its vertical distribution during growth period. Agr. For. Meteorol. 101:237246. 
Shelton, D.P., G.E. Meyer, E.C. Dickey, A. Stepanek, and K.T. Fairbanks. 1988. Electronic image analysis to determine crop residue cover. IFAS, University of Florida.

Smith, D.L., M. Dijak, P. Bulman, B.L. Ma, and C. Hamel. 1999. Barley: Physiology of yield, p. 67-107. In: Smith, D.L. and C. Hamel (eds.). Crop yield, physiology and processes. SpringerVerlag, Berlin, Germany.
Tei, F., A. Scaife, and D.P. Aikman. 1996. Growth of lettuce, onion, and red beet. 1 . Growth analysis, light interception, and radiation use efficiency. Ann. Bot. (Lond.) 78:633643.

White, M.A., G.P. Asner, R.R. Nemani, J.L. Privette, and S.W. Running. 2000. Measuring fractional cover and leaf area index in arid ecosystems: Digital camera, radiation trans- mittance, and laser altimetry methods. Remote Sensing Environmental. 74:45-57.

Wilhelm, W.W., K. Ruwe, and M.R. Schlemmer. 2000. Comparison of three leaf area index meters in a corn canopy. Crop Sci. 41:11791183.

Williams, W.A., R.S. Loomis, and C.R. Lepley. 1965. Vegetative growth of corn as affected by population density. Crop Sci. 5:211-215. 